\title{
MRI Services in Ontario: Is Evidence-Based Planning Currently Feasible?
}

Numerous reports suggest that wait lists for diagnostic tests such as MRI are long and growing in Ontario, and Canada as a whole (Esmail and Walker 2002; McDonald et al. 1998; Ontario Association of Radiologists 2002; Statistics Canada 2002). To address this concern, the Romanow report (2002) recommended national increased funding for diagnostic tests, while the Ontario Ministry of Health and Long-Term Care (MOHLTC) authorized the opening of five new independent MRI facilities in Ontario later this year (Government of Ontario 2002). In July 2002, the MOHTLC asked the Institute for Clinical Evaluative Sciences (ICES) to assess the utility of routinely collected administrative data for evidence-based planning of future MRI services.

\section{Background}

An initial literature review found that both Ontario and Canada as a whole have lower rates of MRI scanners per million population than many European countries (Ontario has about 3.7 scanners per million population, while Switzerland and Sweden have 14 and 6.8 scanners per million population, respectively (Olsson 2001)). Further, wait times for $\mathrm{MRI}$ are perceived to be problematic in many jurisdictions worldwide (Olsson 2001; Robling et al. 1997; Szczepur and Clark 2002; Moore and Golding 1992; Hadorn et al. 2002). Some reports commented that merely increasing the number of MRI scanners will not alleviate wait times/demand in the long term, because of expanding uses for MRI and changes in referral patterns caused by increased supply (Sanmartin et al. 2000; Lewis et al. 2000). Attempts to develop general patient priority scales to help alleviate wait times, such as those developed by the Western Canada Waiting List project, have not been successful because of the complex nature of evaluating the need for diagnostic tests (Western Canada Waiting List Project 2001; Western Canada Waiting List Project 2002). The Winnipeg Regional Health Authority currently collects hospital-specific data on a monthly basis that are used for area-based planning and monitoring of a waiting lists (Dalton 2002).

\section{MRI Use in Ontario}

Temporal utilization trends, geographic variation and patient and referring physician characteristics for outpatients receiving $\mathrm{MRI}$ were analyzed using anonymous Ontario
Health Insurance Plan (OHIP) data. MRI utilization and physician-related costs increased $574 \%$ and $835 \%$ respectively from 1992 to 2001 in Ontario; utilization from 1999 to 2001 increased $53 \%$ (Figure 1). In northern Ontario, $42 \%$ of all scans were ordered by family physicians, compared to $17 \%$ in the south. Age- and sex-adjusted MRI rates varied significantly across provincial regions. Northern Ontario and regions around Toronto, London and Ottawa had higher outpatient MRI utilization rates than other areas in 2001. Figure 2 illustrates the regional variation for MRI of the extremities, as an example.

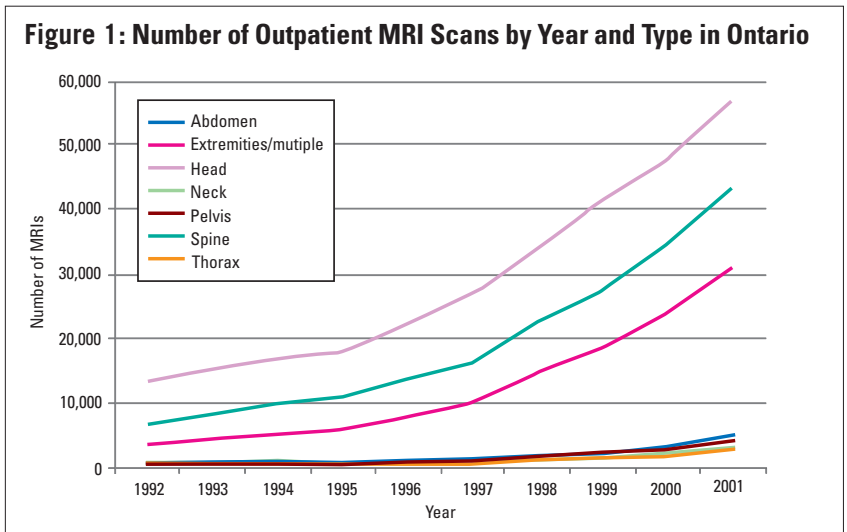

Although the information mentioned above is useful and relatively inexpensive to generate, the data elements necessary for optimal evidence-based planning are not available in Ontario's existing administrative data. For instance, it was not possible to estimate MRI wait times or the appropriateness of ordering an MRI, because the date and reasons that a referring physician ordered an MRI were not available in the claims data. Finally, at the time of our analysis, accurate inpatient MRI data were not available at the patient level.

A fact-finding qualitative interview was conducted with the managers of the MRI centres of Ontario to gain an understanding of the breadth of patient information collected prior to scheduling a scan. All centres that participated in the survey (66\% of all MRI centres) had individualized patient intake forms containing information about the current patient clinical state, medical history and date of referral. 
Figure 2: Age- and Sex-Adjusted MRI (extremities) Rate per 100,000 Population by County (2001) and Location of MRI Scanners in Ontario (2002)
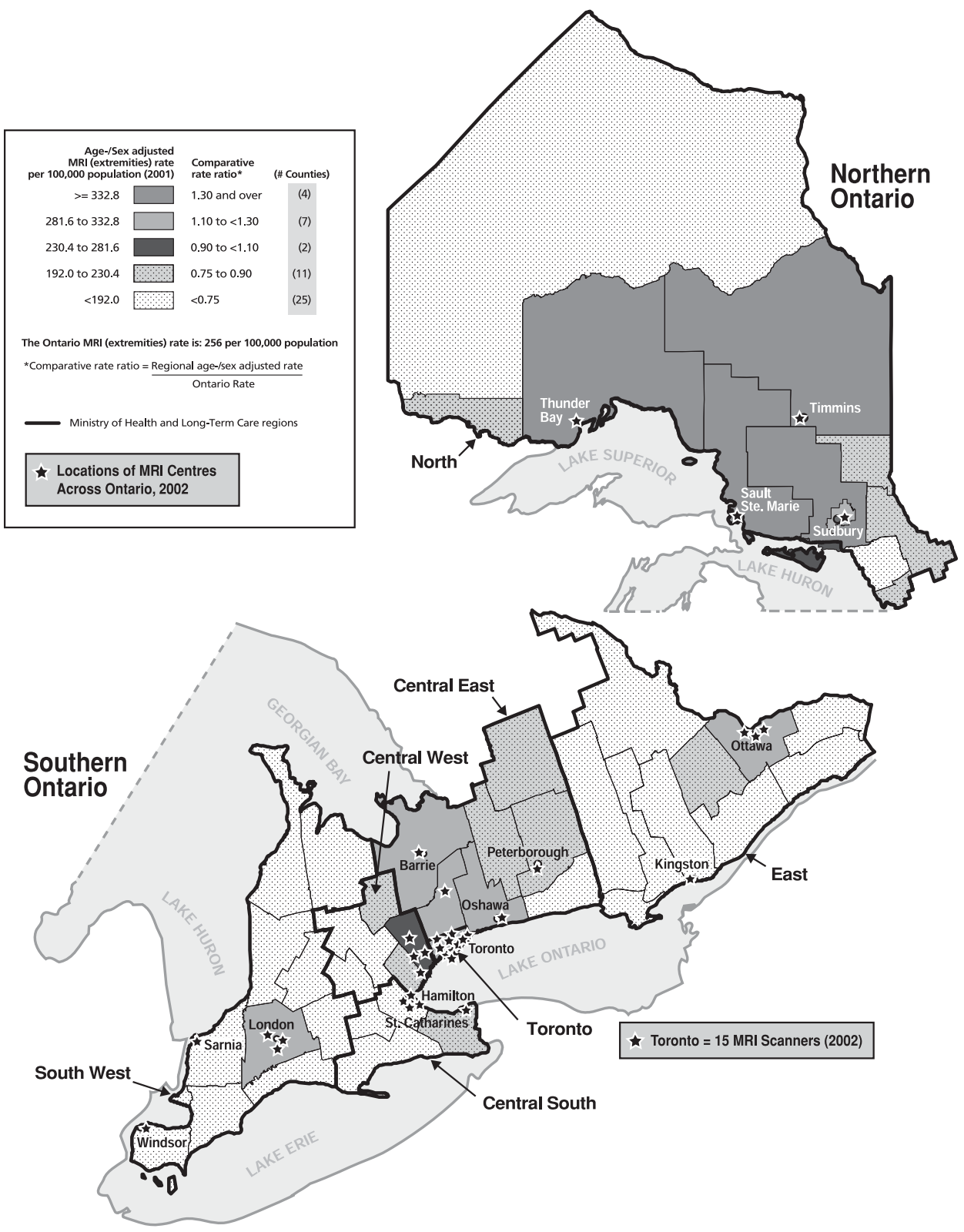

discharge abstract data (DAD) as of April 1, 2003)

- patient presentation and reasons for ordering the $\mathrm{MRI}$

- wait time (the date when the scan was ordered by referring physician)

- impact of MRI on patient outcomes

These limitations represent a significant gap in the evidence required to support up-to-date planning, decision-making and public awareness about MRI services in Ontario.

\section{Recommendations}

To improve access and provision of MRI, consideration should be given to establishing a centrally managed, standardized data collection tool to be used at all MRI centres in Ontario (both hospital-based and independent facilities). With the cooperation of all parties involved, this could be developed quickly, since the current Ontario MRI centres already collect these data in one form or another.

The complete report, Access to $M R I$ in Ontario: Addressing the Information Gap can be found online at www.ices.on.ca

\section{References}

Dalton, Catherine. 2002. Diagnostic Imaging Program Waiting List Status Report. September 30.

Esmail, N. and M. Walker. 2002. Waiting Your Turn: Hospital Waiting

\section{Limits}

Administrative data was useful to monitor outpatient MRI utilization trends. However, at the time of our report existing gaps in the routinely collected data did not allow for the analysis of the following information:

- inpatient data (however, in a recent response to the full ICES MRI report released in March, 2003, the MOHLTC will require hospitals to submit inpatient $\mathrm{MRI}, \mathrm{CT}$ and coronary angiography information as part of the $\mathrm{CIHI}$ hospital
Lists in Canada. 12th edition. British Columbia: The Fraser Institute. Government of Ontario. 2002. Ontario One Step Closer to Increased Access to MRIs and CT Scans. Retrieved December 2002. www. newswire.ca/government/ontario/english/ releases/November2002/15/c2406.htm

Hadorn, D.C. and the Steering Committee of the Western Canada Waiting List Project. 2002. "Developing Priority Criteria for Magnetic Resonance Imaging: Results from the Western Canada Waiting List Project." JACR 53(4): 210-18.

Lewis, S., M.L. Barer, C. Sanmartin, S. Sheps, S.E.D. Shortt and P.W. McDonald. 2000. "Ending Waiting-List Mismanagement: Principles 
and Practice." CMAJ 162(9): 1297-1300.

McDonald, P., S.E.D. Shortt, C. Sanmartin, M. Barer, S. Lewis and S. Sheps, eds. 1998. "Waiting Lists and Waiting Times for Health Care in Canada: More Management!! More Money??" Ottawa: Health Canada. Moore, N.R., S. J. Golding and The Oxford MRI Group. 1992. "Increasing Patient Throughput in Magnetic Resonance Imaging: A Practical Approach." The Br J of Rad 65: 470-75.

Olsson, S. 2001. "Diffusion, Utilisation and Regional Variations in the Use of CT and MRI in Sweden." Computer Methods and Programs in Biomedicine 66: 29-135.

Ontario Association of Radiologists. 2002. "CT/MRI Needs Assessment Report: Expansion Plan for CT/MRI Services in Ontario Hospitals." 2002. Retrieved November 2002. www.oar.info/html/CTMRINEEDSASSESSMENTRPT2.pdf

Robling, M., P. Kinnersley, H. Houston, M. Hourihan, D. Cohen and J. Hale. 1997. "An Exploration of GPs' Use of MRI: A Critical Incident Study." Family Practice 15(3): 236-43.

Romanow, R.J. 2002. "Building on Values: The Future of Health Care in Canada." Ottawa: Commission on the Future of Health Care in Canada.

Sanmartin, C., S.E.D. Shortt, M.L. Barer, S. Sheps, S. Lewis and P.W. McDonald. 2000. "Waiting for Medical Services in Canada: Lots of Heat, but Little Light." CMAJ 162(9): 1305-10.

Statistics Canada. 2002. Health Services Access Survey. Retrieved January 2003. www.statcan.ca/english/sdds/5002.htm

Szczepur, A., M. Clark. 2002. "Creating a Strategic Management Plan for Magnetic Resonance Imaging (MRI) Provision." Health Policy 53: 91-104.

Western Canada Waiting List Project. 2001. "From Chaos to Order: Making Sense of Waiting Lists in Canada." Final report.

Western Canada Waiting List Project. 2002. "Phase 2 Pilot Projects: Workshop Proceedings."

\section{About the Authors}

Karey Iron, MHSc is Senior Research Coordinator, ICES.

Andreas Laupacis, MD, MSc, FRCPC is President and CEO, ICES.

Paula McColgan, BSc, MHA, CHE is Director, Policy and External Relations, ICES.

Raymond Przybysz, MSc is Research Coordinator, ICES.

Get the Longwoods $\boldsymbol{e}$-letter to receive updates on new publications, new papers and new learning events. Free. To subscribe go to www.longwoods.com/mailinglist

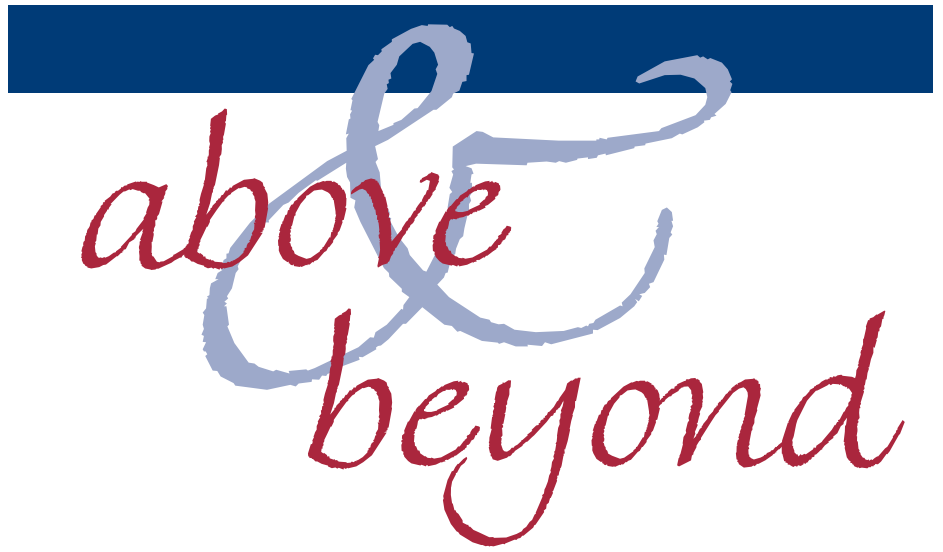

THE CALL OF DUTY

The recent SARS outbreak sent waves of concern through the health care system in Ontario. At Cambridge Memorial Hospital, this meant extra work, long hours, difficult working conditions and stressful circumstances for hundreds of health care professionals.

We are grateful to our physicians, staff and volunteers, who responded to this crisis with dedication and compassion. We're proud to have you on our team.

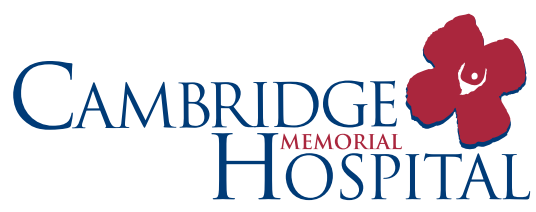

Hope. Healing. Making a Real difference.

\section{5| 9-62|-2330 - www.cmh.org}

The publication of this journal is supported by an educational grant from Hewlett-Packard (Canada) Co. 